\title{
Molecular characterization of clinical carbapenem-resistant Enterobacterales from Qatar
}

\author{
Fatma Ben Abid ${ }^{1,2,3}$. Clement K. M. Tsui ${ }^{3,4,5}$ - Yohei Doi ${ }^{6,7}$. Anand Deshmukh ${ }^{8}$. Christi L. McElheny ${ }^{6}$. \\ William C. Bachman ${ }^{6}$. Erin L. Fowler ${ }^{6} \cdot$ Ahmed Albishawi $^{1,2} \cdot$ Kamran Mushtaq $^{9} \cdot$ Emad B. Ibrahim $^{8}$. \\ Sanjay H. Doiphode ${ }^{8}$. Manal M. Hamed ${ }^{8}$ - Muna A. Almaslmani ${ }^{1,2}$ - Abdullatif Alkhal ${ }^{1,2}$. \\ Adeel A. Butt ${ }^{3,9}$. Ali S. Omrani ${ }^{1,2,10}$
}

Received: 26 November 2020 / Accepted: 3 February 2021 / Published online: 22 February 2021

(C) The Author(s) 2021

\begin{abstract}
One hundred forty-nine carbapenem-resistant Enterobacterales from clinical samples obtained between April 2014 and November 2017 were subjected to whole genome sequencing and multi-locus sequence typing. Klebsiella pneumoniae (81, $54.4 \%)$ and Escherichia coli $(38,25.5 \%)$ were the most common species. Genes encoding metallo- $\beta$-lactamases were detected in $68(45.8 \%)$ isolates, and OXA-48-like enzymes in $60(40.3 \%) . b l a_{\text {NDM-1 }}(45 ; 30.2 \%)$ and $b l a_{\text {OXA-48 }}(29 ; 19.5 \%)$ were the most frequent. KPC-encoding genes were identified in $5(3.6 \%)$ isolates. Most common sequence types were E. coli ST410 (8; $21.1 \%)$ and ST38 (7; 18.4\%), and K. pneumoniae ST147 (13; 16\%) and ST231 $(7 ; 8.6 \%)$.
\end{abstract}

Keywords CRE $\cdot$ Carbapenemase $\cdot \mathrm{KPC} \cdot \mathrm{NDM} \cdot \mathrm{VIM} \cdot \mathrm{OXA} \cdot$ Enterobacterales $\cdot$ Qatar $\cdot$ Middle East

\section{Introduction}

Considerable variations exist in the epidemiology of carbapenemases in Enterobacterales from different parts of the world [1]. Awareness of the locally prevalent carbapenemases is relevant to the appropriate selection of antimicrobial therapy for carbapenem-resistant Enterobacterales (CRE) infections [2]. Moreover, the molecular epidemiology of CRE could help guide control efforts. The aim of this study was to identify the predominant carbapenemases in CRE from Qatar and to elucidate their molecular epidemiology.

Fatma Ben Abid

fabid@hamad.qa

1 Division of Infectious Diseases, Department of Medicine, Hamad Medical Corporation, Doha, Qatar

2 Communicable Diseases Center, Hamad Medical Corporation, PO Box 3050, Doha, Qatar

3 Weill Cornell Medicine-Qatar, Doha, Qatar

4 Department of Pathology, Sidra Medicine, Doha, Qatar

5 Division of Infectious Diseases, Faculty of Medicine, University of British Columbia, Vancouver, Canada

\section{Methods}

All carbapenem-resistant Enterobacterales isolates from clinical specimens received at Hamad Medical Corporation Microbiology Department during the period between April 2014 and November 2017 were included. The department provides diagnostic microbiology services for all public hospitals in Qatar. Laboratory methods for bacterial identification, antimicrobial susceptibility testing, whole genome sequencing and analysis are described in the supplementary data file.

Division of Infectious Diseases, University of Pittsburgh School of Medicine, Pittsburgh, PA, USA

7 Departments of Microbiology and Infectious Diseases, Fujita Health University School of Medicine, Toyoake, Japan

8 Division of Microbiology, Department of Pathology and Laboratory Medicine, Hamad Medical Corporation, Doha, Qatar

9 Department of Medicine, Hamad Medical Corporation, Doha, Qatar

10 Clinical Epidemiology Research Unit, Hamad Medical Corporation, Doha, Qatar 


\section{Results}

A total of 149 non-repetitive CRE clinical isolates from 146 patients were included. The median patient age was 57 years (range, 3 months -97 years), and 77 (52.7\%) were males. Diabetes mellitus $(73 ; 50 \%)$ and chronic kidney diseases $(39 ; 26.7 \%)$ were the most frequent co-existing medical conditions. Nineteen (12.8\%) isolates were recovered from samples obtained within the first $24 \mathrm{~h}$ of hospitalization. Nearly one-fifth of the patients $(25,17.1 \%)$ had entered the country from overseas within 30 days prior to CRE isolation. Further demographic and clinical details are provided in Table 1 and in Table $\mathrm{S} 1$ in the supplementary data file.

The most frequent species were Klebsiella pneumoniae (81; 54.4\%) and Escherichia coli $(38 ; 25.5 \%)$ (Table 2), whereas urine $(41 ; 27.5 \%)$ and blood $(33 ; 22.1 \%)$ were the most frequent site of isolation (Table 1). Thirty-four (23.3\%) patients died within 30 days of first CRE isolation. The majority of isolates were susceptible to tigecycline $(129 ; 86.5 \%)$, fosfomycin $(126 ; 84.6 \%)$, and amikacin $(108 ; 72.4 \%)$ (Table S2 in the supplementary data file).

Genes encoding Class B carbapenemases (i.e., metallo- $\beta$ lactamases $[\mathrm{MBL}])$ were detected in $68(45.8 \%)$ isolates, and Class D carbapenemases in 60 (40.3\%). The most frequently identified carbapenemase genes were $b l a_{\mathrm{NDM}-1}(45 ; 30.2 \%)$ and $b l a_{\text {OXA-48 }}(29 ; 19.5 \%)$ (Table 3$)$. KPC-encoding genes were identified in $5(3.6 \%)$ isolates. All 5 patients from whom KPC-producing $K$. pneumoniae were isolated had received medical care abroad within the preceding 30 days (Table S3 in the supplementary data file). No carbapenemase genes were detected in $14(9.4 \%)$ isolates, and 8 (5.3\%) carried more than one carbapenemase genes (Table 2).

The included E. coli isolates belonged to 16 different sequence types, the most frequent of which were ST410 (8; $21.1 \%)$ and ST38 $(7 ; 18.4 \%)$. On the other hand, K. pneumoniae isolates represented 40 different sequence types, most frequently ST147 (13; 16\%) and ST231 (7; 8.6\%). K. quasipneumoniae belonged mainly to ST196 (9; $56.3 \%)$ and ST1416 (4;25\%). Except for $K$. quasipneumoniae, strains with the same sequence type mostly possessed different carbapenemase genes (Table 3).

\section{Discussion}

Typical risk factors for multidrug-resistant Gram-negative infections were highly prevalent in the patients from whom the isolates were retrieved [3]. The observed 30-day all-cause mortality of $23.3 \%$ is consistent with existing literature describing clinical outcomes in patients with CRE infections [4].

The most common carbapenemase genes in this study were those encoding MBL, especially NDM-1 and NDM-7. Effective antimicrobial therapy options for MBL-producing
Enterobacterales are very limited and their management remains particularly challenging [5]. NDM enzymes are established in CRE from the Arabian Peninsula [6, 7]. Given that more than half of the country's residents originate from the Indian Subcontinent, the high prevalence of NDM in CRE from Qatar is not surprising. NDM genes are commonly cocarried with other carbapenemase genes [5]. In this study, NDM genes were present in all eight isolates that possessed multiple carbapenemase genes.

VIM-producing Enterobacterales are endemic in Greece and Eastern Europe, but are otherwise relatively rare [8]. In this study, VIM genes were present in two E. cloacae isolates. VIM carbapenemases have also been reported in K. pneumoniae and E. cloacae from Turkey, Kuwait, and Saudi Arabia $[7,9,10]$. bla IMP-26 $_{\text {was detected in a single }}$ E. coli isolate in this study. IMP-producing Enterobacterales are endemic in Japan, but are rarely detected in CRE from the Middle East [11].

OXA-48-like $\beta$-lactamases are wide-spread in the Arabian Peninsula and the Middle East [6]. Likewise, nearly two-fifth of isolates in this study possessed OXA-encoding genes. Some, but not all, Class D $\beta$-lactamases have carbapenemase hydrolyzing activity [12]. Notably, $30.2 \%$ of our isolates, all of which possessed OXA-48-like genes, were susceptible to meropenem. As previously well-documented, nonsusceptibility to ertapenem is often the most sensitive indicator of carbapenemase production [13]. Similar to previous reports of frequent co-presence of OXA-48-like enzymes with MBL, seven out of eight isolates with multiple carbapenemase genes in this study possessed genes encoding NDM and OXA-48-like enzymes [12, 14].

OXA-181 and OXA-232 are OXA-48-like carbapenemases. OXA-181 differs from OXA-48 by four amino acids and, like $\mathrm{NDM}$, its origin is epidemiologically linked to the Indian subcontinent [12]. In the Middle East region, OXA-181 was previously identified in CRE from Lebanon and Oman [14, 15]. OXA-232 differs from OXA-48 by five amino acids substitutions, and from OXA-181 by one mutation [12]. It was first reported in K. pneumoniae from France, but has since been reported from many parts of the world including South Asia and North Africa $[16,17]$. Interestingly, OXA-232 is often present in K. pneumoniae ST231 [18]. Four out of 10 OXA232-producing $K$. pneumoniae in our study belonged to this sequence type. One meropenem-susceptible $E$. coli isolate in this report possessed $b l a_{\text {OXA-244. }}$ OXA-244 is a single-point mutation derivative of OXA-48, with weaker carbapenem hydrolyzing activity [12]. First described in K. pneumoniae from Spain, OXA-244 is now disseminated in E. coli in many countries in Western Europe [19].

An important finding in this study is the presence of KPCencoding genes in five $K$. pneumoniae isolates, all of which were recovered from patients who had recently received medical care in KPC-endemic regions. KPC enzymes have 
Table 1 Patient demographics and clinical outcome
Variable

Number $(\%)$

(149 isolates from 146 patients)

Demographics

Median age in (range)

57 years ( 3 months -97 years)

Male sex

$77(52.7 \%)$

Nationality of origin*

Eastern Mediterranean Region $\quad 96(65.7 \%)$

South East-Asia Region

European Region

$41(28.1 \%)$

Regions of the Americas

$3(2 \%)$

$1(0.7 \%)$

Comorbidities

Diabetes mellitus

$73(50 \%)$

Chronic kidney disease

$39(26.7 \%)$

Congestive heart failure

$20(13.7 \%)$

Chronic liver disease

$9(6.1 \%)$

$7(4.8 \%)$

$20(13.7 \%)$

$11(7.5 \%)$

$11(7.5 \%)$

$4(2.7 \%)$

$16(10.9 \%)$

$15(10.3 \%)$

$15(10.3 \%)$

$45(30.8 \%)$

Carbapenem therapy within 30 days of CRE isolation

$41(28.1 \%)$

Surgical procedure

$29(19.8 \%)$

Central line insertion

$29(19.8 \%)$

Urinary catheterization

$11(7.5 \%)$

Other risk factors for CRE infection

Presence of central venous catheter $\quad 42(28.7 \%)$

Total parenteral nutrition

$5(3.4 \%)$

$41(28.1 \%)$

$25(17.1 \%)$

Travel within 30 days of CRE isolation

$41(28.1 \%)$

Urinary tract

$33(22.6 \%)$

$17(11.6 \%)$

$8(5.5 \%)$

$14(9.6 \%)$

Others

$34(23.3 \%)$

$38(26 \%)$

Clinical outcome

Death within 30 days from CRE isolation

Recurrence with 30 days

*World Health Organization Regions. CRE, carbapenem-resistant Enterobacterales

historically been rare in the Middle East, except in Egypt and Israel [1]. However, reports have recently emerged of their occasional detection in CRE from Saudi Arabia, and the United Arab Emirates [20, 21]. In common with our report, the isolation of KPC-producing K. pneumoniae in Saudi Arabia was associated with recent travel to Egypt, a country where KPC-producing Enterobacterales are endemic [1,20]. Travel generally, and medical tourism in particular, has 
Table 2 Carbapenemase genes detected in the study isolates

\begin{tabular}{|c|c|c|c|c|c|c|}
\hline Carbapenemase genes & $\begin{array}{l}\text { All isolates } \\
(n=149)\end{array}$ & $\begin{array}{l}\text { E. coli } \\
(n=38)\end{array}$ & $\begin{array}{l}\text { K. pneumoniae } \\
(n=81)\end{array}$ & $\begin{array}{l}\text { K. quasipneumoniae } \\
(n=16)\end{array}$ & $\begin{array}{l}\text { E. cloacae } \\
(n=7)\end{array}$ & $\begin{array}{l}\text { Others* } \\
(n=7)\end{array}$ \\
\hline Class A & $4(2.7 \%)$ & 0 & $4(4.9 \%)$ & 0 & 0 & 0 \\
\hline$b l a_{\mathrm{KPC}-2}$ & $3(2.0 \%)$ & - & $3(3.7 \%)$ & - & - & - \\
\hline$b l a_{\mathrm{KPC}-3}$ & $1(0.7 \%)$ & - & $1(1.2 \%)$ & - & - & - \\
\hline Class B & $64(43.0 \%)$ & $14(36.8 \%)$ & $24(29.6 \%)$ & $16(100 \%)$ & $6(85.7 \%)$ & $4(57.1 \%)$ \\
\hline$b l a_{\mathrm{IMP}-26}$ & $1(0.6 \%)$ & $1(2.6 \%)$ & - & - & - & - \\
\hline$b l a_{\mathrm{NDM}-1}$ & $45(30.2 \%)$ & $3(7.9 \%)$ & $22(27.2 \%)$ & $14(87.5 \%)$ & $4(57.1 \%)$ & $2^{\dagger}(28.6 \%)$ \\
\hline$b l a_{\mathrm{NDM}-5}$ & $7(4.7 \%)$ & $7(18.4 \%)$ & - & - & - & - \\
\hline$b l a_{\mathrm{NDM}-6}$ & $1(0.7 \%)$ & $1(2.6 \%)$ & - & - & - & - \\
\hline$b l a_{\mathrm{NDM}-7}$ & $5(3.4 \%)$ & - & $1(1.2 \%)$ & $2(12.5 \%)$ & - & $2^{\ddagger}(28.6 \%)$ \\
\hline$b l a_{\mathrm{NDM}-13}$ & $1(0.7 \%)$ & $1(2.6 \%)$ & - & - & - & - \\
\hline$b l a_{\mathrm{NDM}-19}$ & $1(0.7 \%)$ & $1(2.6 \%)$ & - & - & - & - \\
\hline$b l a_{\mathrm{VIM}-2}$ & $1(0.7 \%)$ & - & $1(1.2 \%)$ & - & - & - \\
\hline$b l a_{\mathrm{VIM}-4}$ & $2(1.3 \%)$ & - & - & - & $2(28.6 \%)$ & - \\
\hline Class D & $59(39.6 \%)$ & $21(55.2 \%)$ & $34(42 \%)$ & 0 & $1(14.3 \%)$ & $2(28.6 \%)$ \\
\hline$b l a_{\text {OXA-48 }}$ & $29(19.5 \%)$ & $10(26.3 \%)$ & $16(19.8 \%)$ & - & $1(12.3 \%)$ & $2^{\S}(28.6 \%)$ \\
\hline$b l a_{\text {OXA-181 }}$ & $19(12.8 \%)$ & $10(26.3 \%)$ & $9(11.1 \%)$ & - & - & - \\
\hline$b l a_{\text {OXA-232 }}$ & $10(6.7 \%)$ & - & $10(12.3 \%)$ & - & - & - \\
\hline$b l a_{\mathrm{OXA}-244}$ & $1(0.7 \%)$ & $1(2.6 \%)$ & - & - & - & - \\
\hline Multiple carbapenemases & $8(5.3 \%)$ & $1(2.6 \%)$ & $7(8.6 \%)$ & 0 & 0 & $1(14.3 \%)$ \\
\hline$b l a_{\mathrm{NDM}-1}+b l a_{\mathrm{KPC}-3}$ & $1(0.7 \%)$ & - & $1(1.2 \%)$ & - & - & - \\
\hline$b l a_{\mathrm{NDM}-1}+b l a_{\mathrm{OXA}-181}$ & $2(1.3 \%)$ & - & $2(2.5 \%)$ & - & - & - \\
\hline$b l a_{\mathrm{NDM}-5}+b l a_{\mathrm{OXA}-48}$ & $3(2.0 \%)$ & - & $3(3.7 \%)$ & - & - & - \\
\hline$b l a_{\mathrm{NDM}-5}+b l a_{\mathrm{OXA}-181}$ & $2(1.3 \%)$ & $1(2.6 \%)$ & $1(1.2 \%)$ & - & - & - \\
\hline None & $14(9.4 \%)$ & $1(2.6 \%)$ & $12(14.8 \%)$ & - & - & $1 \Phi(12.3 \%)$ \\
\hline
\end{tabular}

*Klebsiella aerogenes (2), Providencia spp. (2), Citrobacter freundii (1), Klebsiella oxytoca (1), and Proteus mirabilis (1)

${ }^{\dagger}$ Providencia sp. (1), P. mirabilis (1)

${ }^{\star}$ C. freundii (1), Providencia sp. (1)

${ }^{\S}$ K. oxytoca $(1), K$. aerogenes $(1)$

${ }^{\mathbb{I}} \mathrm{K}$. aerogenes (1)

frequently been implicated in international importation of multidrug-resistant pathogens [1]. No carbapenemaseencoding genes were detected in $9.4 \%$ of the isolates included in this study. It is likely that resistance in those isolates was mediated by non-carbapenemase mechanisms [22].

Tigecycline, fosfomycin, and aminoglycoside were the most active agents against the study isolates. Despite their in vitro activity, these agents' clinical utility is limited by reduced efficacy in certain infection sites, excessive toxicity, or rapid emergence of resistance [2]. Ceftazidime-avibactam was recently introduced into clinical practice in Qatar. This $\beta$-lac$\operatorname{tam} / \beta$-lactamase inhibitor combination is active against most Enterobacterales producing Class A and Class D carbapenemases [2]. However, the introduction of ceftazidime-avibactam to intensive care units in Greece was followed by a change in the pattern of carbapenemases in CRE from $b l a_{\mathrm{KPC}}$ to $b l a_{\mathrm{VIM}}$ predominance [23]. Given the background high prevalence of MBL in CRE in Qatar, such agents should be used judiciously to minimize the risk of selection of MBL producers.

The study isolates belonged to widely diverse sequence types. Only two international multidrug-resistant high-risk clones were relatively common: E. coli ST38 and K. pneumoniae ST147. However, other important high-risk clones were either infrequent (i.e., E. coli ST131, ST405, and ST648; and K. pneumoniae ST14, and ST258) or absent (e.g., E. coli ST69, ST155, and ST393; and K. pneumoniae ST14) [24]. These observations suggest that rather than clonal expansion, sporadic introductions of CRE and plasmidmediated dissemination of carbapenemases are the main drivers of CRE epidemiology in Qatar. There are numerous examples of inter-species transmission of carbapenemase genes on mobile genetic elements resulting in in vivo emergence of resistance in individual patients, and also driving 
Table 3 Study isolates by their sequence type and carbapenemase genes

\begin{tabular}{|c|c|c|}
\hline Species & Sequence type (number of isolates) & Carbapenemase-encoding genes (number of isolates) \\
\hline \multirow[t]{17}{*}{ E. $\operatorname{coli}(n=38)$} & ST10 (2) & bla $_{\mathrm{NDM}-5}(1)$, none $(1)$ \\
\hline & ST23 (1) & $b l a_{\text {OXA-48 }}(1)$ \\
\hline & ST38 (7) & $b l a_{\mathrm{OXA}-48}(6), b l a_{\mathrm{OXA}-181}(1)$ \\
\hline & ST58 (1) & $b l a_{\text {OXA-48 }}(1)$ \\
\hline & ST101 (2) & $b l a_{\mathrm{NDM}-1}(1)$, none $(1)$ \\
\hline & ST131 (1) & $b l a_{\mathrm{IMP}-26}(1)$ \\
\hline & ST167 (3) & $b l a_{\mathrm{NDM}-1}(1), b l a_{\mathrm{NDM}-13}(1), b l a_{\mathrm{NDM}-19}(1)$ \\
\hline & ST361 (1) & $b l a_{\mathrm{NDM}-5}(1)$ \\
\hline & ST405 (2) & $b l a_{\mathrm{OXA}-48}(1), b l a_{\mathrm{NDM}-5}(1)$ \\
\hline & ST410 (8) & $b l a_{\mathrm{OXA}-181}(7), b l a_{\mathrm{NDM}-5}$ and $b l a_{\mathrm{OXA}-181}(1)$ \\
\hline & ST617 (2) & $b l a_{\mathrm{NDM}-5}(2)$ \\
\hline & ST648 (2) & $b l a_{\text {OXA-48 }}(1), b l a_{\text {OXA-244 }}(1)$ \\
\hline & ST940 (1) & $b l a_{\mathrm{NDM}-1}(1)$ \\
\hline & ST1487 (2) & $b l a_{\mathrm{NDM}-5}(1), b l a_{\mathrm{OXA}-181}(1)$ \\
\hline & ST1193 (1) & $b l a_{\mathrm{NDM}-5}(1)$ \\
\hline & ST8346 (1) & $b l a_{\mathrm{OXA}-181}(1)$ \\
\hline & Undetermined (1) & $b l a_{\mathrm{NDM}-6}(1)$ \\
\hline \multirow[t]{31}{*}{ K. pneumoniae $(n=81)$} & ST4 (1) & $b l a_{\mathrm{NDM}-1}(1)$ \\
\hline & ST10 (2) & $b l a_{\mathrm{NDM}-5}(1)$, none $(1)$ \\
\hline & ST11 (5) & $b l a_{\mathrm{NDM}-1}(4), b l a_{\mathrm{KPC}-2}(1)$ \\
\hline & ST14 (2) & $b l a_{\mathrm{NDM}-1}(2)$ \\
\hline & ST15 (2) & $b l a_{\mathrm{NDM}-1}(1), b l a_{\mathrm{KPC}-2}(1)$ \\
\hline & ST16 (3) & $b l a_{\mathrm{NDM}-1}+b l a_{\mathrm{OXA}-181}(1), b l a_{\mathrm{OXA}-181}(1), b l a_{\mathrm{OXA}-232}(1)$ \\
\hline & ST17 (1) & $b l a_{\mathrm{NDM}-1}(1)$ \\
\hline & ST35 (1) & $b l a_{\mathrm{OXA}-181}(1)$ \\
\hline & ST38 (1) & $b^{\prime} a_{\mathrm{OXA}-232}(1)$ \\
\hline & ST39 (3) & $b l a_{\mathrm{NDM}-1}(3)$ \\
\hline & ST101 (1) & None (1) \\
\hline & ST147 (13) & 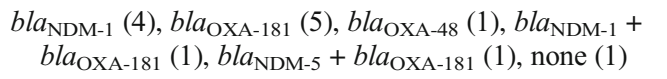 \\
\hline & ST220 (1) & None \\
\hline & ST231 (7) & $b l a_{\text {OXA-232 }}(4), b l a_{\text {OXA-48 }}(1)$, none $(2)$ \\
\hline & ST252 (1) & $b l a_{\mathrm{NDM}-1}(1)$ \\
\hline & ST258 (1) & $b l a_{\mathrm{KPC}-3}(1)$ \\
\hline & ST280 (1) & $b^{\prime} a_{\mathrm{OXA}-48}$ \\
\hline & ST307 (2) & None (2) \\
\hline & ST323 (1) & $b l a_{\mathrm{OXA}-48}$ \\
\hline & ST340 (2) & $b l a_{\mathrm{NDM}-1}(2)$ \\
\hline & ST376 (1) & $b l a_{\text {OXA-48 }}$ \\
\hline & ST383 (4) & $b l a_{\mathrm{OXA}-48}(1), b l a_{\mathrm{NDM}-5}+b l a_{\mathrm{OXA}-48}$ \\
\hline & ST395 (2) & $b l a_{\mathrm{OXA}-232}(1)$, none $(1)$ \\
\hline & ST405 (1) & $b l a_{\text {OXA-48 }}(1)$ \\
\hline & ST420 (2) & $b l a_{\mathrm{OXA}-48}(2)$ \\
\hline & ST432 (1) & $b l a_{\text {OXA-48 }}(1)$ \\
\hline & ST584 (1) & None (1) \\
\hline & ST716 (2) & $b l a_{\text {OXA-48 }}(2)$ \\
\hline & ST873 (1) & $b l a_{\text {OXA-48 }}(1)$ \\
\hline & ST915 (3) & $b l a_{\mathrm{NDM}-1}(3)$ \\
\hline & ST983 (1) & $b l a_{\text {OXA-48 }}(1)$ \\
\hline
\end{tabular}


Table 3 (continued)

\begin{tabular}{|c|c|c|}
\hline Species & Sequence type (number of isolates) & Carbapenemase-encoding genes (number of isolates) \\
\hline & ST985 (1) & None (1) \\
\hline & ST1193 (2) & $b l a_{\mathrm{OXA}-48}(1), b l a_{\mathrm{NDM}-7}(1)$ \\
\hline & ST1418 (1) & $b l a_{\text {OXA-181 }}(1)$ \\
\hline & ST1626 (1) & $b l a_{\mathrm{OXA}-48}(1)$ \\
\hline & ST2096 (2) & $b l a_{\text {OXA-232 }}(2)$ \\
\hline & ST3311 (1) & None (1) \\
\hline & ST5029 (1) & $b l a_{\mathrm{KPC}-2}(1)$ \\
\hline & ST5030 (1) & $b l a_{\mathrm{OXA}-232}(1)$ \\
\hline & ST5031 (1) & bla $_{\mathrm{OXA}-181}(1)$ \\
\hline & Undetermined (2) & $b l a_{\mathrm{KPC}-3}+b l a_{\mathrm{NDM}-1}(1), b l a_{\mathrm{VIM}-2}(1)$ \\
\hline \multirow[t]{5}{*}{ K. quasipneumoniae $(n=16)$} & ST196 (9) & $b^{b l a} a_{\mathrm{NDM}-1}(9)$ \\
\hline & ST1416 (4) & $b l a_{\mathrm{NDM}-1}(4)$ \\
\hline & ST1584 (1) & $b l a_{\mathrm{NDM}-7}(1)$ \\
\hline & ST1998 (1) & $b l a_{\mathrm{NDM}-7}(1)$ \\
\hline & Undetermined (1) & $b l a_{\mathrm{NDM}-1}(1)$ \\
\hline \multirow[t]{5}{*}{ E. cloacae $(n=7)$} & ST66 (1) & $b l a_{\text {OXA-48 }}(1)$ \\
\hline & ST113 (1) & $b l a_{\mathrm{NDM}-1}(1)$ \\
\hline & ST511 (1) & $b l a_{\mathrm{NDM}-1}(1)$ \\
\hline & ST609 (1) & $b l a_{\mathrm{NDM}-1}(1)$ \\
\hline & ST78 (3) & $b l a_{\mathrm{NDM}-1}(1), b l a_{\mathrm{VIM}-4}(2)$ \\
\hline \multirow[t]{2}{*}{$K$. aerogenes $(n=2)$} & ST93 (1) & None (1) \\
\hline & Undetermined (1) & $b^{b l a_{\mathrm{OXA}-48}}(1)$ \\
\hline Providencia sp. $(n=2)$ & Undetermined (1) & $b l a_{\mathrm{NDM}-1}(1), b l a_{\mathrm{NDM}-7}(1)$ \\
\hline C. freundii $(n=1)$ & Undetermined (1) & $b l a_{\mathrm{NDM}-7}(1)$ \\
\hline K. oxytoca $(n=1)$ & Undetermined (1) & $b l a_{\text {OXA-48 }}(1)$ \\
\hline P. mirabilis $(n=1)$ & Undetermined (1) & $b l a_{\mathrm{NDM}-1}(1)$ \\
\hline
\end{tabular}

institutional, national, and international CRE outbreaks [24]. Our findings highlight the epidemiological global interconnectedness of bacterial antimicrobial. Given Qatar's demographics and its position as a major hub for international travel, the findings described here have regional and global implications. The molecular epidemiology of carbapenem resistance in Enterobacterales and its underlying mechanisms should be monitored locally, and interpreted in a global context.

\section{Conclusion}

The most frequent carbapenemases in CRE from Qatar are NDM and OXA-48-like enzymes. KPC, hitherto rare in the Arabian Peninsula, was present in a minority of the isolates, where all cases were associated with recent overseas medical care. CRE from Qatar belonged to diverse sequence types, suggesting limited local clonal expansion. It appears that the epidemiology of CRE in Qatar is largely driven by a combination of sporadic importation and inter-species transfer of mobile genetic elements.

Supplementary Information The online version contains supplementary material available at https://doi.org/10.1007/s10096-021-04185-7.

Availability of data and materials The datasets used and analyzed during the current study are available from the corresponding author on reasonable request. The sequencing data are available from the National Center for Biotechnology Information (NCBI) under the accession number PRJNA627583.

Author contribution Conceptualization, F.B., A.A.B.; methodology, F.B., C.K.M.T., Y.D, and A.S.O.; data curation, F.B., A.D., K.M., and A.A.; investigation, A.D., C.L.M., W.C.B., and E.L.F.; formal analysis, F.B., C.K.M.T., Y.D., and A.S.O.; resources, M.A.A., A.A., and E.B.I.; writing - original draft, A.S.O., F.B., and C.K.M.T.; writing - review and editing, Y.D. and A.A.B.; all authors read and approved the final manuscript.

Funding Open access funding provided by the Qatar National Library. The study was funded by research grants from the Medical Research 
Centre at Hamad Medical Corporation, Doha (MRC-16134/16 to F.B.) and from the National Institutes of Health (R01AI104895, R21AI135522, and R21AI151362 to Y.D.).

\section{Declarations}

Ethics approval The study was approved with a waiver for informed consent by the Institutional Review Board at Hamad Medical Corporation, Doha, Qatar (MRC-16134/16).

Conflict of interest The authors declare no competing interests.

Open Access This article is licensed under a Creative Commons Attribution 4.0 International License, which permits use, sharing, adaptation, distribution and reproduction in any medium or format, as long as you give appropriate credit to the original author(s) and the source, provide a link to the Creative Commons licence, and indicate if changes were made. The images or other third party material in this article are included in the article's Creative Commons licence, unless indicated otherwise in a credit line to the material. If material is not included in the article's Creative Commons licence and your intended use is not permitted by statutory regulation or exceeds the permitted use, you will need to obtain permission directly from the copyright holder. To view a copy of this licence, visit http://creativecommons.org/licenses/by/4.0/.

\section{References}

1. van Duin D, Doi Y (2017) The global epidemiology of carbapenemase-producing Enterobacteriaceae. Virulence 8:460469

2. Doi Y (2019) Treatment options for carbapenem-resistant Gramnegative bacterial infections. Clin Infect Dis 69:S565-SS75

3. Palacios-Baena ZR, Giannella M, Manissero D et al (2020) Risk factors for carbapenem-resistant Gram-negative bacterial infections: a systematic review. Clin Microbiol Infect. https://doi.org/ 10.1016/j.cmi.2020.10.016

4. Zilberberg MD, Nathanson BH, Sulham K et al (2017) Carbapenem resistance, inappropriate empiric treatment and outcomes among patients hospitalized with Enterobacteriaceae urinary tract infection, pneumonia and sepsis. BMC Infect Dis 17:279

5. Boyd SE, Livermore DM, Hooper DC et al (2020) Metallo-betalactamases: structure, function, epidemiology, treatment options, and the development pipeline. Antimicrob Agents Chemother 64: e00397-e00320

6. Sonnevend Á, Ghazawi AA, Hashmey R et al (2015) Characterization of carbapenem-resistant Enterobacteriaceae with high rate of autochthonous transmission in the Arabian Peninsula. PLoS One 10:e131372

7. Memish ZA, Assiri A, Almasri M et al (2015) Molecular characterization of carbapenemase production among gram-negative bacteria in saudi arabia. Microb Drug Resist 21:307-314

8. Matsumura Y, Peirano G, Devinney R et al (2017) Genomic epidemiology of global VIM-producing Enterobacteriaceae. J Antimicrob Chemother 72:2249-2258

9. Cizmeci Z, Aktas E, Otlu B et al (2017) Molecular characterization of carbapenem- resistant Enterobacteriaceae yields increasing rates of NDM-1 carbapenemases and colistin resistance in an OXA-48endemic area. J Chemother 29:344-350
10. Sonnevend Á, Yahfoufi N, Ghazawi A et al (2017) Contribution of horizontal gene transfer to the emergence of VIM-4 carbapenemase producer Enterobacteriaceae in Kuwait. Infect Drug Resist 10:469 478

11. Su HR, Turhan Ö, Erman Daloğlu CA et al (2020) Molecular epidemiology of carbapenem-resistant Enterobacterales strains isolated from blood cultures in Antalya. Turkey. Lab Med. https://doi. org/10.1093/labmed/lmaa017

12. Poirel L, Potron A, Nordmann P (2012) OXA-48-like carbapenemases: the phantom menace. J Antimicrob Chemother 67:1597-1606

13. Clinical Laboratory Standards Institute (2020) Performance standards for antimicrobial susceptibility testing, 30th Edition. CLSI Supplement M100. Available at: http://em100.edaptivedocs.net/ GetDoc.aspx .doc $=$ CLSI\%20 M100\%20ED30:2020\&scope $=$ user.

14. Dortet L, Poirel L, Al Yaqoubi F et al (2012) NDM-1, OXA-48 and OXA-181 carbapenemase-producing Enterobacteriaceae in Sultanate of Oman. Clin Microbiol Infect 18:E144-E148

15. Dagher C, Salloum T, Alousi S et al (2018) Molecular characterization of Carbapenem resistant Escherichia coli recovered from a tertiary hospital in Lebanon. PLoS One 13:e0203323

16. Shankar C, Mathur P, Venkatesan M et al (2019) Rapidly disseminating blaOXA-232 carrying Klebsiella pneumoniae belonging to ST231 in India: multiple and varied mobile genetic elements. BMC Microbiol 19:137

17. Lahlaoui H, Bonnin RA, Moussa MB et al (2017) First report of OXA-232-producing Klebsiella pneumoniae strains in Tunisia. Diagn Microbiol Infect Dis 88:195-197

18. Mancini S, Poirel L, Tritten M-L et al (2017) Emergence of an MDR Klebsiella pneumoniae ST231 producing OXA-232 and RmtF in Switzerland. J Antimicrob Chemother 73:821-823

19. European Centre for Disease Prevention and Control. Rapid risk assessment: increase in OXA -244 -producing Escherichia coli in the European Union/European Economic Area and the UK since 2013 (2020). Available at: https://www.ecdc.europa.eu/en/ publications-data/rapid-risk-assessment-increase-oxa-244producing-escherichia-coli-eu-eea.

20. Alghoribi MF, Binkhamis K, Alswaji AA et al (2020) Genomic analysis of the first KPC-producing Klebsiella pneumoniae isolated from a patient in Riyadh: a new public health concern in Saudi Arabia. J Infect Public Health 13:647-650

21. Sonnevend Á, Ghazawi A, Darwish D et al (2015) Characterization of KPC-type carbapenemase-producing Klebsiella pneumoniae strains isolated in the Arabian Peninsula. J Antimicrob Chemother 70:1592-1593

22. Cerqueira GC, Earl AM, Ernst CM et al (2017) Multi-institute analysis of carbapenem resistance reveals remarkable diversity, unexplained mechanisms, and limited clonal outbreaks. Proc Natl Acad Sci U S A 114:1135-1140

23. Papadimitriou-Olivgeris M, Bartzavali C, Lambropoulou A et al (2019) Reversal of carbapenemase-producing Klebsiella pneumoniae epidemiology from blaKPC- to blaVIM-harbouring isolates in a Greek ICU after introduction of ceftazidime/avibactam. J Antimicrob Chemother 74:2051-2054

24. Mathers AJ, Peirano G, Pitout JD (2015) The role of epidemic resistance plasmids and international high-risk clones in the spread of multidrug-resistant Enterobacteriaceae. Clin Microbiol Rev 28: $565-591$

Publisher's note Springer Nature remains neutral with regard to jurisdictional claims in published maps and institutional affiliations. 